\title{
Diagnostic Work-Up and Etiology in Ischemic Stroke in Young Adults: Before and Now
}

\section{Jose Felipe Varona*}

Department of Internal Medicine, University Hospital "Madrid Monteprincipe", Madrid, Spain

\begin{abstract}
Unlike in the elderly, causes of ischemic stroke in young adults (15-45 years) are diverse. Non-atherosclerotic arteriopathy -dissection of the extra cranial arteries, migraine, drugs, vasculitis, premature atherosclerosis, cardioembolism, hypercoagulable states and cerebral venous thrombosis are the most relevant. Over time, the etiological diagnosis of ischemic stroke in young patients has changed significantly as a result of the improvement in diagnostic workup and the emergence of new risk factors, particularly drug abuse. Current diagnostic investigations allow the identification of specific cardiac, vascular and coagulation abnormalities previously undetectable. Thus, while 3 or 4 decades ago more than half of patients were diagnosed with uncertain etiology, currently less than $20 \%$ are diagnosed with cryptogenic stroke, and half of those with two or more identified potential causes. Specific etiologies, such as non-atherosclerotic vasculopathy, large-artery atherosclerosis, cardioembolism and haematological disorder, are demonstrated in the majority of patients. The scope of the present manuscript is to review the current state of the art, underlying the improvements with respect to the past.
\end{abstract}

Keywords: Ischemic stroke; Diagnostic work-up; Etiology; Young adult

\section{Introduction}

Ischemic stroke in young adults (15-45 years) is relatively frequent, accounting for more than $10 \%$ of all first ischemic strokes). Its causes are heterogeneous and while it generally has a good prognosis, it has a significant socioeconomic impact, including functional deficits and financial costs [1-19].

An accurate etiological diagnosis is crucial for preventing new episodes and additional functional deficits.

Currently, the most frequent causes of ischemic stroke in young adults are cardioembolism, premature atherosclerosis, dissection of extracranial arteries, migraine, drugs and hypercoagulable states $[11,12,15,17]$. However, it has not always been like this, as previously undetermined etiology was by far the most prevalent. Although still common, undetermined etiology is now less frequent as a result of diagnostic improvements $[12,15,16]$.

Observation over time has demonstrated more accurate identification of the causes for ischemic stroke in the young, primarily through changes in epidemiological conditions and improvements in diagnostic tests [15].

\section{Diagnostic Workup: New Technical Tools, New Diagnoses}

Previous series studies of young adults with ischemic stroke cite undetermined as the most frequent etiology, identified in more than $35 \%$ of patients [7-11]. Nevertheless, the improvement in diagnostic workup has changed this panorama (Table 1).

Diagnostic workup has changed dramatically over the last 3-4 decades (Figure 1). Since 1990s, procedures such as transesophageal echocardiography, hypercoagulability testing and magnetic resonance have been included in the systematic diagnostic protocol for stroke in young adults [10-15].

\section{Cerebral Magnetic Resonance Imaging (MRI)}

This technique has allowed significantly improved diagnosis with respect to isolated cranial CT scanning. Magnetic resonance imaging (particularly diffusion-weighted MRI) offers the best sensitivity and spatial resolution and plays an important role in the diagnostic approach of young adults with stroke. It is the optimal neuroradiological technique to confirm ischemic origin, to determine the location and the extent of the lesion, to verify the patency of major neck and intracranial arteries and to exclude eventual underling pathologies [20].

\section{Transesophageal Echocardiography}

This technique shows abnormalities (sources of cardioembolism)

\begin{tabular}{|c|c|c|c|c|c|}
\hline & $\mathbf{n}$ & $\begin{array}{l}\% \text { Athero- } \\
\text { thrombotic }\end{array}$ & $\begin{array}{l}\% \text { Cardio- } \\
\text { embolism }\end{array}$ & $\begin{array}{l}\% \text { Other } \\
\text { specific } \\
\text { causes }\end{array}$ & $\begin{array}{c}\% \\
\text { Undeter- } \\
\text { mined }\end{array}$ \\
\hline Adams et al. [8] & 329 & 18 & 18 & 30 & 34 \\
\hline Carolei et al. [7] & 333 & 33 & 24 & 8 & 35 \\
\hline Kitner et al. [11] & 428 & 16 & 21 & 31 & 32 \\
\hline Varona et al. [15] & 272 & 25 & 17 & 22 & 36 \\
\hline $\begin{array}{c}\text { Bogousslavsky et } \\
\text { al. [5] }\end{array}$ & 202 & 8 & 23 & 46 & 23 \\
\hline Kwon et al. [12] & 149 & 38 & 18 & 27 & 17 \\
\hline Rasura M et al. [16] & 394 & 14 & 34 & 28 & 24 \\
\hline Putaala J el al. [17] & 1.008 & 21 & 20 & 26 & 33 \\
\hline
\end{tabular}

Table 1: Causes of ischemic stroke in young adults in the main series.

*Corresponding author: Jose Felipe Varona, Department of Internal Medicine University Hospital "Madrid Monteprincipe", CEU-San Pablo University Schoo of Medicine and Institute of Applied Molecular Medicine (IMMA), Avenida Montepríncipe 25, Boadilla del Monte 28660 Madrid, Spain, Tel: 0034-699511091 Fax: 0034-91.7089900; E-mail: jfva_varona@yahoo.com, josefelipevarona@ hospitaldemadrid.com

Received May 29, 2012; Accepted June 18, 2012; Published June 21, 2012

Citation: Varona JF (2012) Diagnostic Work-Up and Etiology in Ischemic Stroke in Young Adults: Before and Now. J Neurol Neurophysiol 3:133. doi:10.4172/21559562.1000133

Copyright: (c) 2012 Varona JF. This is an open-access article distributed under the terms of the Creative Commons Attribution License, which permits unrestricted use, distribution, and reproduction in any medium, provided the original author and source are credited. 
Citation: Varona JF (2012) Diagnostic Work-Up and Etiology in Ischemic Stroke in Young Adults: Before and Now. J Neurol Neurophysiol 3:133. doi:10.4172/2155-9562.1000133

in many patients in whom transthoratic study is normal. The importance of transesophageal echocardiography in the etiological evaluation of stroke in young adults has been widely demonstrated. The diagnosis of patent foramen ovale (PFO) is especially relevant, since paradoxical embolism through a PFO is a relatively commonly identified mechanism of stroke in young adults. However, due to the high prevalence of this condition in the general population (20\%) and the frequent identification of other causes of stroke in many patients with PFO and stroke, we must be cautious in interpreting and handling PFO when detected [21-25].

Paradoxically, the improvement in cardiac imaging techniques has not provided an increase in the number of patients diagnosed with cardioembolism (Figure 2), since, in many cases, the detected cardiac abnormalities are of low risk for emboli (an incidental finding more than the origin of stroke) or coexisted with others causes of stroke (undetermined etiology due to multiple possible etiologies). Moreover, the incidence of rheumatic valve disease, prior most significant cause of cardioembolism has dramatically decreased over the last few decades.

\section{Vascular Imaging Studies}

(Like extracranial artery doppler sonography, arteriography and magnetic resonance vascular imaging). These are useful to demonstrate premature atherosclerosis or non-atherosclerotic arteriopathy, including specific vascular abnormalities $[20,25]$.

\section{Extensive Coagulation Testing}

One of the cornerstones in the improvement in etiological diagnosis due to its ability to identify molecular and/or genetic disorders associated with hypercoagulable states such as antiphospholipid antibodies syndrome or prothrombin gene mutation. However, as nongenetic lab test may be unreliable in acute phase of stroke, the most reliable studies use genetic testing to identify patients with inherited thrombophilia $[18,26]$.

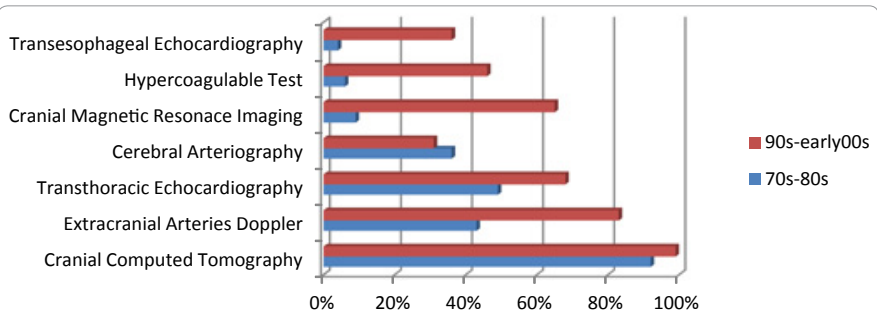

Figure 1: Etiological diagnostic workup performed on patients, according to admission period, based on data of study of Varona et al. [14].

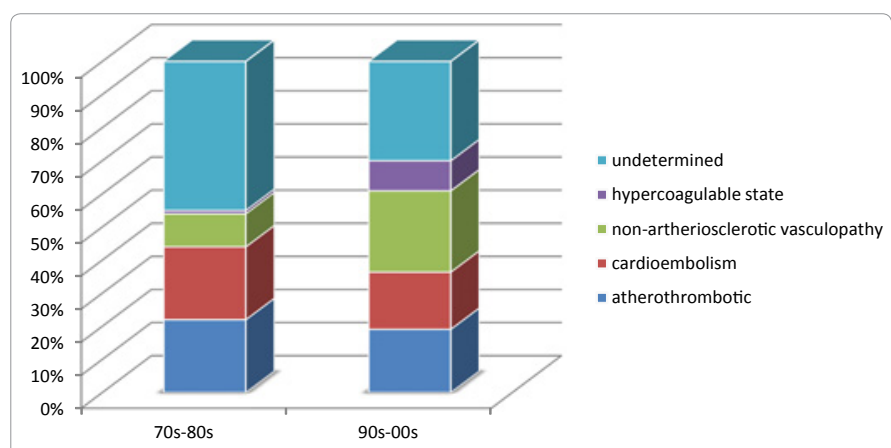

Figure 2: Etiology of ischemic stroke in young adults according evaluation period prior/after 1989, based on data of study of Varona et al. [13,14].

\section{Etiological Diagnosis}

With the standardized use of these procedures, a clear improvement has been made in the etiological diagnostic accuracy (Figure 2). As a result, as the percentage of patients with undetermined etiology has dramatically fallen since 1970-80s, the identification of specific causes (non-atherosclerotic vasculopathy and hypercoagulable state) has increased remarkably [15].

Additionally, and according to TOAST criteria [27-29], the pattern of sub-classification of uncertain etiology has changed significantly over time from incomplete evaluation to negative complete evaluation and multiple contributing factors. This is a very important issue. As uncertain etiology is a very heterogeneous stroke subtype in which causes cannot be determined with any degree of confidence we must be able to subclassify and separate the 3 components of undetermined etiology (Table 2), taking into consideration the different prognoses and management protocols [30]. Although other stroke classifications, such Baltimore-Washington-Cooperative Young Stroke Group [3132] exits for young stroke, the TOAST criteria are the most widely used since their inception in 1993.

More extensive knowledge about infrequent entities such as Fabry disease, hypercoagulable states and mitochondrial diseases and about increasing cardiovascular risk factors like recreational drugs and obesity-prediabetes-metabolic syndrome has contributed to the improvement in diagnostic accuracy.

\section{What about Migraine?}

There is a recognized association between migraine (with or without aura) and ischemic stroke, especially among women taking oral contraceptives and in association with other conditions like patent foramen oval and smoking [33-35]. However, prior to any diagnosis of migraine-related stroke (expanded definition of migrainous infarction, including patients with migraine without aura) we must first exclude other coexisting conditions, as up to $75 \%$ of young adults with stroke and migraine also have other specific causes of ischemia [36,37]. Studies have contradictory findings as some show stable percentages over time [15] while others suggest a decrease with diagnostic improvement [10].

\section{The Future New Biomarkers}

In the last two decades great efforts in research have been focussed in new biomarkers. Emerging novel risk factors such as hyperhomocysteinaemia and thrombophilia may account for up to $20 \%$ of all strokes [38]. In this setting, recent studies have shown novel lipid and lipoprotein biomarkers associated with the risk of ischemic stroke, such as baseline triglycerides, very low-density lipoprotein (VLDL) size, and intermediate-density lipoprotein (IDL) particle number, suggesting new therapeutics targeting [39].

Furthermore, molecular lab testing like proteomics offers great promise for the discovery of biomarkers in the etiological diagnosis of cardiovascular disease and stroke. Some of the identified proteins may be therapeutic targets or biological markers for stroke diagnosis and prognosis [40-42].

\section{Conclusions}

Improvements in diagnostic workup and advances in knowledge about new risk factors and infrequent entities have led to a remarkable increase in the percentage of patients diagnosed with specific causes of 
Citation: Varona JF (2012) Diagnostic Work-Up and Etiology in Ischemic Stroke in Young Adults: Before and Now. J Neurol Neurophysiol 3:133. doi:10.4172/2155-9562.1000133

1) large-vessel atherosclerosis

2) small-vessel disease

3) cardioembolism (due to medium or high risk cardiac embolic source)

4) other specific etiology, including non-atherosclerotic vasculopathies (dissection of extracranial arteries, migraine, inflammatory vasculopathy associated with illicit drugs, infections, connective tissue disease...) and hypercoagulable states

5) undetermined etiology, which was further classified into 3 subtypes

5.a) two or more possible causes identified (undetermined, multiple possible etiologies);

5.b) negative evaluation after exhaustive etiological diagnostic workup which excluded atherothrombotic, lacunar, cardioembolic or specific etiologies; the complete workup includes: cerebral imaging studies as computed tomography (CT) scanning or magnetic resonance imaging, echocardiography, extracranial cerebrovascular Doppler studies, a hemostatic test and arteriography, if needed (undetermined, complete evaluation or unknown etiology)

5.c) incomplete evaluation.

Table 2: Diagnostic categories for ischemic stroke. TOAST criteria.

ischemic stroke. Currently a concrete cause is identified in more than $70-80 \%$ of patients, whereas in the seventies it was possible in less than $50 \%$ of patients.

Procedures such as transesophageal echocardiography, hypercoagulability testing, and magnetic resonance are the cornerstone tools for these improvements, and we must use them in young adults with ischemic stroke to optimize accurate diagnosis and thus appropriate prevention strategies.

However, a significant percentage of patients continue to be diagnosed with undetermined etiology even after extensive evaluation. Thus we must strive further to improve diagnostic evaluation in order to further identify appropriate secondary prevention therapy and to provide proper prognostic assessments.

\section{Acknowledgment}

We gratefully acknowledge the help of Michel Codini in the editing of this manuscript.

\section{References}

1. Hart RG, Miller VT (1983) Cerebral infarction in young adults: a practical approach. Stroke 14: 110-114.

2. Lidegaard O, Sol M, Andersen MV (1986) Cerebral thromboembolism among young women and men in Denmark 1977-1982. Stroke 17: 670-675.

3. Nencini P, Inzitari D, Baruffi MC, Fratiglioni L, Gagliardi R, et al. (1988) Incidence of stroke in young adults in Florence, Italy. Stroke 19: 977-981.

4. Alvarez J, Matias-Guiu J, Sumalla J, Molins M, Insa R, et al. (1989) Ischemic stroke in young adults. I. Analysis of the etiological subgroups. Acta Neurol Scand 80: 28-34.

5. Bogousslavsky J, Pierre P (1992) Ischemic stroke in patients under age 45 . Neurol Clin 10: 113-124.

6. Shriver ME, Prockop LD (1993) The economic approach to the stroke work-up. Curr Opin Neurol Neurosurg 6: 74-77.

7. Carolei A, Marini C, Ferranti E, Frontoni M, Prencipe M, et al. (1993) A prospective study of cerebral ischaemia in the young: analysis of pathogenic determinants. The National Research Council Study Group. Stroke 24: $362-$ 367

8. Adams HP Jr, Kappelle LJ, Biller J, Gordon DL, Love BB, et al. (1995) Ischemic stroke in young adults. Experience in 329 patients enrolled in the lowa Registry of stroke in young adults. Arch Neurol 52: 491-495.

9. Kristensen B, Malm J, Carlberg B, Stegmayr B, Backman C, et al. (1997)
Epidemiology and Etiology of ischemic stroke in young adults aged 18 to 44 years in northern Sweden. Stroke 28: 1702-1709.

10. Martin PJ, Enevoldson TP, Humphrey PR (1997) Causes of the ischaemic stroke in the young. Postgrad Med J 73: 8-16.

11. Kittner SJ, Stern BJ, Wozniak M, Buchholz DW, Earley CJ, et al. (1998) Cerebral infarction in young adults: the Baltimore-Washington Cooperative Young Stroke Study. Neurology 50: 890-894.

12. Kwon SU, Kim JS, Lee JH, Lee MC (2000) Ischemic stroke in Korean young adults. Acta Neurol Scand 101: 19-24.

13. Marini C, Totaro R, De Santis F, Ciancarelli I, Baldassarre M, et al. (2001) Stroke in young adults in the Community-Based L'Aquila registry. Incidence and prognosis. Stroke 32: 52-56.

14. Varona JF, Guerra JM, Bermejo F (2004) Stroke in young adults. Med Clin (Barc) 122: 70-74.

15. Varona JF, Guerra JM, Bermejo F, Molina JA, Gomez de la Cámara A (2007) Causes of ischemic stroke in young adults, and evolution of the etiological diagnosis over the long term. Eur Neurol 57: 212-218.

16. Rasura M, Spalloni A, Ferrari M, De Castro S, Patella R, et al. (2006) A case series of young stroke in Rome. Eur J Neurol 13: 146-152.

17. Putaala J, Metso AJ, Metso TM, Konkola N, Kraemer Y, et al. (2009) Analysis of 1008 consecutive patients aged 15 to 49 with first-ever ischemic stroke: the Helsinki young stroke registry. Stroke 40: 1195-1203.

18. Griffiths D, Sturm J (2011) Epidemiology and etiology of young stroke. Stroke Res Treat.

19. Roger VL, Go AS, Lloyd-Jones DM, Benjamin EJ, Berry JD, et al. (2012) Heart Disease and Stroke Statistics-2012 Update. A Report from the American Heart Association. Circulation 125: e2-e220

20. Uggetti C (2003) Stroke in young people: imaging. Neurol Sci 24: S15-S16.

21. Lechat $P$, Mas JL, Lascault G, Loron P, Theard M, et al. (1988) Prevalence of patent foramen ovale in patients with stroke. N Engl J Med 318: 1148-1152.

22. Kizer JR, Devereux RB (2005) Patent foramen ovale in young adults with unexplained stroke. N Engl J Med 353: 2361-2372.

23. Cramer SC (2005) Patent foramen ovale and stroke: prognosis and treatment in young adults. Thromb Thrombolysis 20: 85-91.

24. Kim D, Saver JL (2005) Patent foramen ovale and stroke: what we do and don't know. Rev Neurol Dis 2: 1-7.

25. Lamy C, Giannesini C, Zuber M, Arquizan C, Meder JF, et al. (2002) Clinica and imaging findings in cryptogenic stroke patients with and without paten foramen ovale: the PFO-ASA Study. Atrial Septal Aneurysm. . Stroke 33: 706711.

26. Ng KW, Loh PK, Sharma VK (2011) Role of investigating thrombophilic disorders in young stroke. Stroke Res Treat 2011: 670138.

27. Adams HP Jr, Bendixen BH, Kappelle LJ, Biller J, Love BB, et al. (1993) Classification of subtype of acute ischemic stroke. Definitions for use in a multicenter clinical trial TOAST. Trial of Org 10172 in Acute Stroke Treatment. Stroke 24: 35-41.

28. Goldstein LB, Jones MR, Matchar DB, Edwards LJ, Hoff J, et al. (2001) Improving the reliability of Stroke group Classification Using the Trial of ORG 10172 in Acute Stroke Treatment (TOAST) Criteria. Stroke 32: 1091-1098.

29. Thrift AG, Dewey HM, Macdonell RA, McNeil JJ, Donnan GA (2001) Incidence of major stroke subtypes: initial finding from the North East Melbourne Stroke Incidence Study (NEMESIS). Stroke 32: 1732-1738.

30. Varona JF, Bermejo F, Guerra JM, Molina JA (2004) Long-term prognosis of ischemic stroke in young adults. Study of 272 cases. J Neurol 251: 1507-1514

31. Rohr J, Kittner S, Feeser B, Hebel JR, Whyte MG, et al. (1996) Traditiona risk factors and ischemic stroke in young adults: the Baltimore-Washington Cooperative Young Stroke Study. Arch Neurol 53: 603-607

32. Johnson CJ, Kittner SJ, McCarter RJ, Sloan MA, Stern BJ, et al. (1995) 
Citation: Varona JF (2012) Diagnostic Work-Up and Etiology in Ischemic Stroke in Young Adults: Before and Now. J Neurol Neurophysiol 3:133. doi:10.4172/2155-9562.1000133

Page 4 of 4

Interrater reliability of an etiologic classification of ischemic stroke. Stroke 26 : 46-51.

33. Etminan M, Takkouche B, Isorna FC, Samii A (2005) Risk of ischemic stroke in people with migraine: systematic review and meta-analysis of observational studies. BMJ 330: 63

34. Pezzini A, Del Zotto E, Giossi A, Volonghi I, Costa P, et al. (2010) The migraineischemic stroke relation in young adults. Stroke Res Treat 2011: 304921.

35. Bousser MG (2004) Estrogens, migraine, and stroke. Stroke 35: 2652-2656.

36. Biller J, Adams HP Jr (1987) Diagnosis of stroke in young adults. Postgrad Med 81: 141-144.

37. Shuaib A (1991) Stroke from other etiologies masquerading as migraine stroke Stroke 22: 1068-1074.
38. Hankey GJ (2006) Potential new risk factors for ischemic stroke. Stroke 37 2181-2188.

39. Berger JS, McGinn AP, Howard BV, Kuller L, Manson JE, et al. (2012) Lipid and lipoprotein biomarkers and the risk of ischemic stroke in postmenopausa women. Stroke 43: 958-966.

40. Gwinn-Hardy H, Dawson V (2004) Genomics-Proteomics and stroke. Stroke 35: $2731-2734$.

41. Hortin GL, Jortani SA, Ritchie JC Jr, Valdes R Jr, Chan DW (2006) Proteomics a new diagnostic frontier. Clin Chem 52: 1218-1222.

42. Cuadrado E, Rosell A, Colomé N, Hernández-Guillamon M, García-Berrocoso T, et al. (2010) The proteome of human brain after ischemic stroke. J Neuropathol Exp Neurol 69: 1105-1115. 